\title{
L. Observations and experiments on the Noctiluca miliaris, the animalcular source of the phosphorescence of the British Seas; together with a few general remarks on the phœnomena of vital phosphorescence
}

\section{James H. Pring M.D.}

To cite this article: James H. Pring M.D. (1849) L. Observations and experiments on the Noctiluca miliaris, the animalcular source of the phosphorescence of the British Seas; together with a few general remarks on the phœnomena of vital phosphorescence, Philosophical Magazine Series 3, 35:238, 401-421, DOI: 10.1080/14786444908646382

To link to this article: http://dx.doi.org/10.1080/14786444908646382

\section{Published online: 30 Apr 2009.}

\section{Submit your article to this journal 둔}

Џ Article views: 2 
THE

\section{LONDON, EDINBURGH AND DUBLIN \\ PHILOSOPHICAL MAGAZINE}

A N D

JOURNAL OF SCIENCE.

\section{[THIRD SERIES.]}

$D E C E M B E R \quad 184.9$.

L. Observations and Experiments on the Noctiluca miliaris, the Animalcular source of the Phosphorescence of the British Seas; together with a few general remarks on the phcenomena of Vital Phosphorescence. By James H. Pring, M.D.*

"A third kind of light arises, no doubt, from living animals which float in the sea, and which must be produced by their peculiar organization, or rather their component parts, which deserve to be better examined by chemical experiment." -Tilloch's Magazine, vol. viii. 1800 .

THE occasional phosphorescence of ocean-water has been the subject of observation amongst naturalists from the days of Pliny down to the present time. The phænomenon is peculiar to no sea, and though most brilliant between the tropics, yet it occurs also in the frozen ocean of either pole, and, as may be readily inferred, in every intermediate grade of clime.

Very graphic and highly interesting are the accounts which travellers and others have given of this remarkable appearance; and various are the opinions which have at different times been advanced in explanation of its cause.

It has been conjectured that, during the shining of the sun, light is absorbed hy the ocean, and that the extrication of it again renders the water luminous, in a manner analogous to the action exemplified by Canton's pyrophorus, the Bononian stones, \&c., or to that which has been termed " insolation."

Again, it has been supposed to depend upon a peculiar electrical state of the atmosphere, or that the ocean itself is at times capable of manifesting this light, as the result of a highly electrical condition of its waters; this last opinion, extraordinary as it may now appear, having enrolled the name of Buffon amongst its supporters.

* Communicated by the Author, having been read before the British Association at Birmingham, September 1849.

Phil. Mag. S. 3. Vol. 35. No. 238. Dec. 1849. 2 D 
The attrition of the saline particles against each other, or some unknown combination amongst them, has also been regarded as a source of this marine light, whilst it has further been attributed to the presence of phosphoric matter extricated from decomposing fish, \&c.; and lastly, it has been very generally referred, especially in recent times, to a power of phosphorescence possessed by numerous living marine animals, similar, for the most part, in its character to that exhibited by the glow-worm and fire-fly on land.

It is almost needless to observe, that, of the foregoing theories, the last may now be said to be universally admitted as correct; yet it is surprising that even with some of those who have investigated the subject in a scientific point of view, no very distinct ideas seem to be entertained as to the precise nature, even in the instance of our own seas, of the animalcular source to which the light is thus in general terms ascribed; whilst the notions prevalent amongst sailors and otbers serve only to exhibit how little has as yet been done towards removing the popular ignorance in which the subject still remains enveloped.

Amongst the scientific world again, we find that investigation has chiefly been directed to those instances of vital phosphorescence which are presented by that division of the animal kingdom which is confined to the land; yet this division sinks into comparative insignificance when contrasted with the great variety and infinite multitudes of phosphorescent animals which inhabit the ocean.

With a view, however, to rendering the present notice more complete, we shall glance rapidly at some of the more prominent instances of phosphorescence as displayed by land animals, and then notice briefly some of the more inportant instances afforded by the tribes inhabiting the sea; dwelling more particularly, as regards the latter, on the example which forms the chief subject of the present communication, the Noctiluca miliaris, to which the phosphorescence occasionally witnessed in the British seas is mainly attributable.

If we except the instance of the Great American Bittern amongst birds, which has been stated to possess the power of " emitting a light from its breast equal to that of a common torch, which illuminates the water so as to enable it to discover its prey *," we are not aware that the property of phosphorescence has been attributed to any land animals until we descend so low in the scale as the class of Insects; a division, however, in which this power is very numerously and conspicuously displayed, the family of the Lampyridæ, or glow-worms alone containing about 200 species known to be luminous, whilst

* See Loudon's Magazine of Natural History, vol. ii. p. 200. 
the number of the Elateridæ, or fire-flies, possessing the same faculty, amounts to at least thirty. Nor are these the only families endowed with this singular power: it is exhibited likewise by the Scarabæides, and is found also in the Pausus spharocerus, the Scolopendra electrica, and in several species of the Fulgora or lantern-flies. 'The ova also of some of these, as in the Lampyris splendidula, are said to be luminous, and the pupa and larva of this insect are reputed to possess the same property, though in a less marked degree. It has been stated also that the common centipede of this country has been observed to be slightly luminous, and the same has been affirmed of the common earth-worm; but these statements require further confirmation before they can be received with confidence.

Before quitting this division of our subject, it may be observed that it is usual, in physiological writings, to find reference made under the present head to the instances of luminosity in the living human subject which were brought under the notice of the profession a few years since by Sir Henry Marsh (Prov. Med. Journ. 1842). The instances in question, however, though highly interesting to the patholugist, like the fact remarked by Cabanis of the excess of phosphorus in the brain of maniacs, are nevertheless of a character which must exclude them from our present inquiry.

Passing then from the examples of phosphorescence thus brought rapidly under view, as exhibited by that portion of the animal creation confined to the land, we proceed briefly to notice the instances of the same phænomenon as displayed amongst the tenants of the deep. And here, as led on in the pursuit of this interesting subject to seek the ocean as the field of his further research, the curious inquirer cannot fail to be struck with the vastness and grandeur of the change presented to his contemplation. Here he discovers not only a much greater variety as regards the range and type of animal life amongst which this power of phosphorescence is distributed, but he will recognize some individual iustances, which, though so minute as to be revealed only by the aid of the microscope, yet exist in such countless myriads, that the whole element may be said to teem with them.

In order to convey some idea of the general effect of the phosphorescence of the ocean from the presence of a great variety of luminous animals, and as witnessed on a large scale at sea, I shall avail myself of some of the descriptions which have been furnished us by travellers of accurate observation and authenticity. In a highly interesting narrative of a whaling voyage round the globe, from the year 1833 to 1836 , $2 \mathrm{D} 2$ 
by F. D. Bennett, Surgeon to the Expedition, we find the following account of the phænomenon:-

"During a dark and calm night, with transient squalls of rain, in lat. $43^{\circ} \mathrm{S}$. long. $79^{\circ} \mathrm{W}$., the sea presented an unusually luminous appearance. While undisturbed, the ocean emitted a faint gleam from its bosom, and when agitated by the passage of the ship flashed forth streams of light which illuminated the sails, and shone in the wake with great intensity. A net, towing alongside, had the appearance of a ball of fire followed by a long and sparkling train ; and large fish, as they darted through the water, conld be traced by the scintillating lines they left upon its surface*." And again, "At midnight, on the 1 st of December, in lat. $19^{\circ} \mathrm{N}$. long. $107^{\circ} \mathrm{W}$. (half-way between the group of the Revilla-gigedo and the continent of America), the sea around us presented one uniform milk-white and luminons expanse, as far as the eye could see from the mast-head. It emitted a faint light like that which attends the dawn of day, and bore a near resemblance to a field of snow reflecting the rays of the moon; the horizon being strongly defined, by the contrast of its bright and silver hue with the murky darkness of the sky above. Close to the ship the water appeared brighter than elsewhere, and the dashing of the waves against her bows produced brilliant flashes of light; but it occurred very strangely, that although the waves could be heard lifting in the ordinary manner, it was difficult to perceive them; and the sea appeared as one tranquil unbroken surface. $A$ net and a bucket were employed to ascertain the cause of this phænomenon. The former captured nothing but a few Medusæ of no phosphorescent power; and the water taken up by the bucket, though it was thickly studded by luminous points, contained no tangible bodies.

"A shoal of porpoises came around us at this time; and as they sported in the luminous ocean, darting rapidly beneath the surface, their dark bodies enveloped, as it were, in liquid fire, they tended to complete a scene, which, if correctly pictured, would appear rather as the fiction of a fairy tale than the effect of natural causest."

In a small work entitled 'The Ocean,' by Mr. P. H. Gosse, we have also an interesting notice of the same appearance, which is thus described:- " The most usual appearances, as far as they have fallen under my own observation in the Atlantic, are as follow:-On looking over the stern, when the ship has steerage-way, her track is visible by a line or belt of light, not a bright glare, but a soft, subdued, yellowish light, 
which immediately under the eye resembles milk, or looks as though the keel stirred up a sediment of chalk which diffuses itself in opake clouds through the neighbouring water, only that it is light and not whiteness. Scattered about this cloudiness, and particularly where the water whirls and eddies with the motion of the rudder, are seen innumerable sparks of light distinctly traced above the mass by their brilliancy, some of which vanish and others appear, while others seem to remain visible for some time. Generally speaking, both these phænomena are excited by the action of the vessel through the waves, though a few sparks may be observed on the surface of the waves around. But now and then, when a short sea is running without breaking waves, there are seen broad flashes of light from the surface of a wave, coming and going like sudden fitful flashes of lightning. These may be traced as far as the eye can reach, and in their intermittent gleams are very beautiful ; they have no connexion with the motion of the ship*."

When we inquire more precisely into the particular sources of this marine light, we find it distributed, as before mentioned, far more extensively amongst the various grades of animal life in the ocean, than amongst those of the land. Although the fact has been somewhat called in question, and the light attributed to the disturbance of the surrounding luminous water, yet there appears little doubt that the power of phosphorescence is actually possessed by animals ranking as high as the class of fishes. Thus in the narrative of Mr. F. D. Bennett, above alluded to, after referring the general luminosity of the ocean on a particular occasion to the presence of Medusæ, he proceeds: "Though the discovery of these Medusæ was a satisfactory explanation of the phosphorescent appearance of the water, I had yet to learn that the latter effect was partly produced by living, bony, and perfectly organized fish : such fish were numerous in the sea this night; and a tow-net captured ten of them in the space of a few hours. They were a species of Scopelus, three inches in length, covered with scales of a steel-gray colour, and the fins spotted with gray. Each side of the margin of the abdomen was occupied by a single row of small and circular depressions of the same metallicgray hue as the scales; a few similar depressions being scattered also on the sides, but with less regularity. The examples we obtained were alive when taken from the net, and swam about actively upon being placed in a vessel of seawater. When handled or swimming, they emitted a vivid phosphorescent light from the scales, or plates, covering the body and head, as well as from the circular depressions on the

* Page 355. 
abdomen and sides, and which presented the appearance of as many small stars spangling the surface of the skin. The luminous gleam (which had sometimes an intermittent or twinkling character, and at others shone steadily for several minutes together) entirely disappeared after the death of the fish." It is almost needless to observe that there appears little room for questioning a fact thus minutely and accurately described. Another instance belonging to the Shark tribe, (the Squalus frilgens) has also formed the subject of minute investigation by the same observer. After describing the form and structure of this fish, and noting accurately the portions of the body devoted to the production of the light, he remarks, "I am inclined to believe that the luminous power of this shark resides in a peculiar secretion from the skin. It was my first impression that the fish had accidentally contracted some phosphorescent matter from the sea, or from the net in which it was captured; but the most rigid investigation did not confirm this suspicion; while the uniformity with which the luminous gleam occupied certain portions of the body and fins, its permanence during life, and decline and cessation upon the approach and occurrence of death, did not leave a doubt in my mind but that it was a vital principle, essential to the œconomy of the animal."

Many of the Crustacea, of which the Cancer fulgens and the Oniscus fulgens may serve as examples, are universally admitted to be highly luminous. The Mollusca, both testaceous and naked, afford well-marked instances of phosphorescence. Amongst the former, examples of which are somewhat rare, may be noticed the Cleodora cuspidata, described more particularly by $\mathrm{Mr}$. Bennett, and also some of the Pholades, \&c.; whilst the latter contain the Salpæ, the Pyrosomata, \&c. Amongst the Annelida we find the Nereides and the Polynö̈ fulgurans enjoying the same faculty; and the same may be observed very generally of the Acalephæ, the general phosphorescence of the ocean being chiefly due to the numerous kinds of Medusa, Polypiferæ, Rotiferæ, and Infusoria included under this class, and more particularly in our own seas to the microscopic example it contains, the Noctiluca miliaris, which brings us to the special object of the present communication.

In noticing more particularly this minute yet powerful source of oceanic light, I shall first give a brief account of the general appearance imparted by its presence to the waters of our bay, as exbibited for several successive nights during the months of July and August last, and then describe more particularly the little animal itself, and the various experiments to which it has been subjected. 
Taking, as a good example, the night of the 9th of August last, which was remarkably bright and cloudless, and at the same time serene and mild, the phosphorescence of the waters of our bay, which had been visible in a less degree for many preceding nights, assumed about midnight a very brilliant and beautiful appearance. Seen from a distance, the aspect presented at this time by the whole surface of the water was that of a diffused silvery light, which caused the dark headland of Brean Down, on the opposite side of the bay, to appear as if laved by liquid silver. On approaching nearer the water's edge, so as to observe more distinctly the waves as they broke gently and with even regularity upon the strand, the effect can only be compared to masses of liquid fire rolling and pouring in, and diffusing itself along the shore. On the north-west point of the bay is a projecting rock called Knightstone, joined by a raised causeway to the main land, and forming at high water a sort of short pier, alongside of which a few small vessels and boats usually lie at anchor. The shelter against the current; together with the shade afforded by the rock and walls of the pier, combined to prove highly favourable to an observation of the effect in comparatively still water, and under increased darkness. On looking down then at this point, between the sides of the vessels and the rock, a constant scintillation was to be observed on the surface of the water, very similar to a shower of fire or sparks, the luminous points, some larger, others less in size, perpetually dancing up as it were to the surface, and soon again disappearing to be replaced by others. The larger points, some of which were as large as a pea, were produced, I conceive, from several of the little animals having floated into close approximation or contact, whilst the smaller ones, I imagine, proceeded from detached individuals.

On striking the surface of the water lightly with an oar, not only the spot immediately touched, but also all the water dashed up, appeared, whilst raised in the air, and again on falling into the surrounding water, to bear an exact resemblance to liquid fire, affording a spectacle of the most brilliant description. Several bottles were then filled with the water from this spot where it appeared brightest. I likewise procured a bucketful of the same kind, and the whole was brought home for the purposes of observation and experiment. As tending to convey some further idea of the luminous power of the water in its natural condition, it may be mentioned that on rendering my room perfectly dark and agitating the water in one of these bottles, it perfectly illuminated any object in its vicinity, so as to enable me to distinguish various 
objects on my table, pictures hanging against the wall, \&c.; the luminous effect, however, being very transitory, and only at the moment of agitation.

Viewed the following morning by daylight, innumerable very minute gelatinous bodies, of a globular form, could be perceived even with the naked eye, floating near the surface of the water; and on gently shaking the bottle containing them, they could be ubserved to descend to a short depth, gradually, however, rising again to their former level when left at rest. From repeated observation of this fact, it would appear that these little animals are naturally, or otherwise possess the power of rendering themselves, specifically lighter than sea water; and this property appears to be a living attribute, since it ceases, and they are seen immediately to sink to the bottom of the vessel, upon the occurrence of death.

Placed under the field of a microscope, and magnified to about the size of a large pea, the Noctiluca presented the appearance of a highly delicate and translucent membranous sac, of almost spherical form, and having the look on one side as if the mouth of the sac had been puckered up and turned inwards; yet this puckered part does not take an exactly circular form corresponding to a description which has been given of it, as "producing such an appearance as would arise from tying the neck of a round bag and turning it into the water ;" but extends rather in a longitudinal direction, giving somewhat the effect of a longitudinal cleft; and from one end of this cleft is observed to protrude a lengthened filamentous body, which seems to be a sort of tentaculum, and during the life of the animal is seen to be in almost constant motion.

I have endeavoured in vain to obtain a more accurate view of this appendage; but the state of constant motion it is in, together with the extreme minuteness and delicacy of the whole animal, have hitherto rendered my efforts unavailing. That it is occasionally employed as an organ of locomotion there can be no question, and some of the movements executed by it have appeared to me very surprising. Thus I have witnessed it extended above the animal, and then used as a fulcrum, as it were, to draw the body of the miliaris. Natural size,
animal upwards towards itself; yet of an inch in diameter.

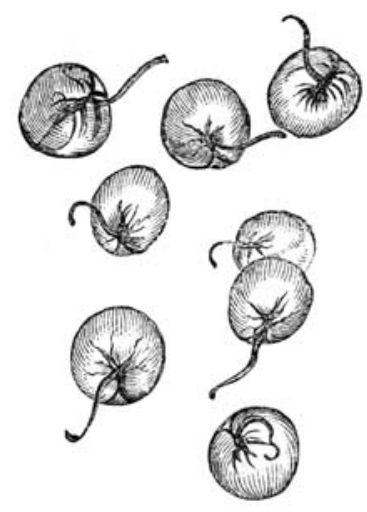

Magnified view of the Noctiluca miliaris. Natural size, 1 $\frac{2}{20}$ th part of an inch in diameter. 
by what power so fine and hair-like a member can be made to oppose such resistance to the water, as that the comparatively large globular mass composing the body of the animal should be drawn to it, rather than that it should pass to the globe, I am unable to determine with precision, and consequently refrain from offering a merely conjectural opinion.

The method of examination which $I$ have found to be the most convenient, and from which the foregoing description is taken, is to pour a small quantity of the luminous water into a watch-glass and then submit it to the microscope, by which means the little animals still remain floating in the water, and their movements, under the eye of the observer, are in no way interfered with. Examined in this manner, there is nothing to be discovered to indicate any special luminous organ, or the precise part of the animal devoted to the production of the light; but in several specimens I could clearly observe a mass of loose flocculent mucus adhering to the part which has been described as being puckered in, and more immediately near the insertion of the tentaculum; so that $I$ am disposed to believe that the phosphorescent principle resides in this mucus, and is probably most vivid at the moment of its secretion, the secretion itself appearing to be influenced and thrown out more abundantly under circumstances indicating danger, serving thus to account for the brilliancy with which the light is manifested on first agitating the water after it has been allowed to remain some time at rest. It seems probable, also, that the motion of the tentaculum may at times contribute somewhat to the effect, by disturbing the mucus, and thus bringing a newly-exposed surface of it into contact with the water; the occasional scintillations to be witnessed, even where the water is under circumstances of perfect repose, being, in all probability, thus produced.

The extreme minuteness and delicacy of this little animal (its natural size being stated not to exceed the $\frac{1}{1000}$ th part of an inch in diameter), have no doubt been the causes that have interfered to prevent its attracting any great share of popular attention; and which have also occasioned its being frequently overlooked, as formerly stated, even by scientific observers. Thus, in the passage formerly quoted from the work of Mr. F. D. Bennett, he mentions that a bucket of water which had been taken up, "though thickly studded with luminous points, contained no tangible bodies;" there can be little doubt that these "luminous points" were in reality due to the presence of these minute Noctilucæ; and the same remark may also be extended to a similar passage which occurs at p. 321, vol. ii. of the same work. In some cases, on the other hand, it would 
appenr that the same animal has been alluded to, but under a different title. Thus, although, it must be confessed, imperfect in its details, no one can read the description given by Macartney of the Medusa sciutillans, without recognizing its full applicabllity, as far as it goes, to the subject of the present notice. Two other instances, the Medusa hemispharica and the Beroë fulgens, are also described by Macartney as occasionally to be met with in the British seas; but their comparative rarity has led this author himself to regard the minuter example, of which we are now treating, as " the most frequent source of the light of the sea around this country," and even also " in other parts of the world." Passing, then, from these general considerations as regards the animal itself, we shall proceed to detail the varions experiments to which it has been subjected, which may be most conveniently treated of in the following order, viz.-1, experiments subjecting the luminous water to the action of galvanism; 2 , to the action of various gases; 3 , to the action of the strong mineral acids; 4 , to the action of æther and chloroform, \&c.

1. Effects of Galvanism and Electro-magnetism.-Subjected to a simple galvanic current from two of Smee's batteries, no very perceptible effect could be observed to be produced. I then attached an electro-magnetic coil to the batteries, and thus passed the electro-magnetic current through the water for some time: at first no very appreciable result appeared to follow; but in a short time a steady and continued glow of light was given out from the whole of the water, the surface of which appeared further as if spangled with numberless minute but persistent points of light. After a short time the light began to grow more faint, and in a quarter of an hour had ceased altogether, without the possibility of its being reproduced, the loss of the light being evidently dependent upon the death of the animalculæ.

2. Gases. Effects of Oxygen.-On filling a bottle with oxygen gas, and allowing some of the gas to escape so as to be replaced by a portion of the luminous sea-water, the phosphorescence of the Noctilucæ contained in the latter could be perceived to be sensibly increased when the water was agitated with the oxygen, but no continuous or persistent glow of light followed this experiment. For upwards of a week, however, the little animals continued to live beneath this atmosphere of oxygen, evidently emitting, on agitation, for several successive nights during which the observations were continued, the same tmount of increased light as had been observed to occur in he first instance.

Effects of Nitrogen.--Subjected to the influence of nitrogen, 
in the same way as has just been described with respect to oxygen, the resnlts were much less marked than might have been anticipated. The Noctilucæ confined beneath the nitrogen continued to live, and to display a vivid phosphorescence when the bottle was agitated for above the space of a week after the experiment was first instituted. If any difference could be ubserved between this experiment and the former, it was that the brilliancy of the light was somewhat less in this than in the former, being probably about equal to what it would have been if atmospheric air had been employed in place of nitrogen.

Effects of Nitrous Oxide Gas.-On being submitted in the same manner to the action of this gas, the Noctilucæ appeared to be no otberwise affected than under a similar employment of atmospheric air. They were alive and phosphorescent at the end of ten days from the cummencement of the experiment. The intensity of the phosphorescence, however, appeared to be neither augmented nor diminished by the action of this gas.

Effects of Sulphuretted Hydrogen Gas.-On treating a portion of the luminous water with this gas, the phosphorescence was instantly destroyed, all the Noctiluce being immediately killed; thus further demonstrating and establishing the wellknown power of destructiveness to animal life which characterizes this gas.

Effects of Carbonic Acid Gas.--Of all the gases hitherto noticed, the carbonic acid is the most remarkable in its effects on the luminous sea water. Having filled a bottle with this gas, and introduced it under the water so as to allow a portion of the gas to escape and be replaced by the water, in the same manner as in the other instances just related, the luminous property of the water was not only brought out and highly incrensed, but was rendered permanent for at least a quarter of an hour, during which time the effect might be compared to a bright incandescent glow, of sufficient intensity to render the bottle visible from a distant part of the room; and when approached more nearly, to enable me to discein the hands of a watch by the sole aid of the light thus afforded. At about the expiration of fifteen minutes the light became gradually fainter, and in about twenty or twenty-five minutes had totally ceased; the darkness, as in the other cases, being evidently connected with the death of the animalculæ, which on being brought into the light, could be seen lying at the bottom of the vessel.

A sęcond bottle of this gas was then procured and employed in the same way, for the purpose of ascertaining the effect of 
the admission of atmospheric air, at the time when the phosphorescent glow was beginning to grow faint. The result, however, did not appear to be in any way influenced, nor was the light in any degree resuscitated by this variation of the experiment.

Effects of Hydrogen.-Submitted to the action of this gas, no very marked effect appeared to be produced upon the water. On agitating a portion of it in a bottle containing this gas, numerous specks of light, indicating the presence of the animalculæ, could be perceived for many successive nights; but the light appeared somewhat less vivid in its character than that afforded with atmospheric air, or in the instance before mentioned, in which pure nitrogen was employed.

Effects of Atmospheric Air.-The influence of atmospheric air is here introduced merely as affording a standard of comparison with the effects obtained from the employment of the gases. A bottle of the luminous water, procured at the same time as that used in the preceding experiments, retained its luminosity a few days longer when subjected only to atmospheric air, than under the employment of any of the abovementioned gases; but the phosphorescence was only to be observed on the occurrence of any agitation of the water. It appears also that the luminous property is retained longer when the vessel or bottle containing the water is kept closed or corked, than when it is left entirely open and freely exposed to the action of the air.

3. Effects of the strong Mineral Acids.-For the purpose of ascertaining whether the phosphorescence would be in any way affected by the strong mineral acids, a small quantity of water was placed in each of three glass vessels, and then a few drops of acid were added to the water in each vessel, this latter part of the experiment being of course conducted in the dark. On letting fall a few drops of strong sulphuric acid into the water, the latter immediately emitted a bright light which remained for the space of a ninute or two, after which it almost immediately disappeared.

The effect of strong nitric acid appeared in no way to differ from that produced by the sulphuric acid; but treated with strong hydrochloric acid in the same manner, the increased luminosity of the water was much less conspicuous than in either of the former instances, and the darkness ensued almost instantaneously.

Effects of AEther and Chloroform.-A few drops of æther dropped into the sea-water in the dark appeared instantly to deprive it of its luminous property, no degree of agitation to which it was subjected being found capable of eliciting the 
smallest scintillation after the addition of the æther. On substituting chloroform, however, in the second experiment in the place of the æther, a very bright and persistent phosphorescence was given out for the space of a few minutes, after which the water speedily became dark, the animalculæ being evidently killed. Before taking leave of this division of the subject, it may be as well to notice the influence simply of fresh water upon the Noctilucæ. On pouring some of the sea-water, rendered luminous by the presence of these little animals, into a vessel already containing some fresh rain-water, a subdued continuous glow was given out from several luminous points for a short period, during which the specks of light were seen to subside to the bottom of the vessel, and very speedily afterwards to become totally extinguished.

Of the foregoing experiments, those connected with the employment of the gases appear to be the most interesting; and any degree of importance they may possess will be best appreciated from their bearing upon the topics now to be brought under notice, in the form of a few concluding remarks of a general character on the

Phenomena of Vital Phosphorescence. - The development of light as the result of a vital function, and as constituting an essential feature in the oconomy of some forms of animal life, is a phænomenon of so interesting and remarkable a nature, that it could not fail to arrest the attention of naturalists and philosophers in almost every age. It is, however, only since the impulse which the cultivation of chemical science received about the latter part of the last century, that the subject has come to be investigated in the true spirit of scientific inquiry. It was about the period here alluded to, also, that the animalcular source of the phosphorescence of the sea was first indisputably established; and some valuable papers appeared on the subject in the excellent journal conducted by $\mathrm{Mr}$. Tilloch. At this time, however, no higher object appears to have been sought, than the mere establishment of the fact, as just stated, of the dependence of the phosphorescence of the sea upon an animalcular origin. Many individual instances of phosphorescent marine animals were, indeed, adduced in support of the new doctrine; but this was done without much method or accuracy of detail; and the minuteness and transparency of the little animal which forms the subject of the present notice appear to have occasioned its being at that time overlooked.

At a period, then, when the fact of the animalcular source of marine phosphorescence was barely admitted, and may be said to have been almost a question still sub judice, it was scarcely 
to be expected that those forms of animal life, whose very existence was held to be problematical, should themselves be made the subjects of actual experiment; and it is accordingly among those more undoubted and easily accessible examples afforded by the insects to be found on the land, that the study of the phænomena of vital phosphorescence has been chiefly prosecuted; the glow-worm and the fire-fly having been generally selected for the purposes of experimental investigation, from the period in question even down to the present time.

Thus, in the second edition of Chaptal's Chemistry, published so long since as the year 1795 , we read that " $\mathrm{Mr}$. Forster of Göttingen found that the light of glow-worms is so beautiful and bright in oxygenous gas, that one single insect was sufficient to afford light to read the Annonces Savantes of Göttingen, printed in very small character." The same fact is likewise referred to, and ably commented on, in an excellent paper on the phosphorescence of the Luciole (Lampyris Italica) by Dr. Carradori, in the second volume of Tilloch's Magazine; and similar notices are thus incidentally to be met with interspersed throughout the mass of physiological and chemical writings with which science is now enriched. It is, however, to Professor Matteucci that we are indebted for the most accurate and comprehensive experiments that have hitherto been undertaken in connexion with this department of inquiry ; and although still confined principally to the glowworm, his observations may fairly be assumed to afford the best exposition of the existing state of knowledge on the subject of phosphorescence now extant; and I must accordingly refer to his valuable lectures, as published by Pereira, all those who may be desirous of becoming acquainted with the minute structure of the phosphorescent organs of the glowworm, and such other topics as do not appear to fall strictly within the design of the present paper.

On conparing the results obtained from the action of various gases on the Noctiluca, as described in a former part of this communication, with the effects produced by the same agents upon the glow-worm as recorded by Professor Matteucci, some very remarkable differences will be found to present themselves to our observation. It is right, however, to bear in mind the different circumstances under which the experiments are necessarily conducted in the two instances; the animalculæ in the former, being brought into contact with the gas only through the medium of the water in which they float; whereas in the case of the glow-worm, the insect is freely and entirely exposed to the gas in which it is immersed.

Bearing in mind, then, and making suitable allowance for 
this difference of circumstance in the two instances, we shall proceed to note some of the more remarkable points of contrast which they present to us, and which may be thus summarily enumerated.

As in the instances recorded by Matteucci and other observers, with respect to the glow-worm, so with regard to the Noctilucæ under consideration, the phosphorescence was found to be remarkably increased by oxygen; in the former, however, not only was the light increased in brilliancy, but also in duration; whereas we have seen that the Noctiluca, confined under an atmosphere of oxygen, died somewhat sooner than those confined in a bottle containing atmospheric air.

In hydrogen, glow-worms are found to lose their phosphorescence at furthest in about twenty-five or thirty minutes; whilst the Noctiluce, under an atmosphere of this gas, continued to emit scintillations at the end of eight or nine days from the commencement of the experiment. But it is in respect to carbonic acid gas that the most remarkable contrast is exhibited in the two cases. On placing glow-worms in this gas, Prof. Matteucci found that in a few minutes the light entirely disappeared; whereas, in the case of the Noctilucæ, we have seen that there is no agent which has the effect of increasing the brilliancy of the light so powerfully as this gas, at the same time that the bright phosphorescent glow formerly described is rendered permanent for the space of fifteen or twenty minutes. After the lapse of this time, however, this gas proves as fatal to the Noctiluce, as to the glow-worm; and to the former, without the power exhibited by the latter, of resuscitation of the light by the admission of atmospheric air.

The effects of sulphuretted hydrogen gas appear to be precisely the same on the glow-worm and on the Noctiluca, both being very speedily destroyed by it.

Although those which have now been cited appear to be the only instances which offer a fair opportunity for direct comparison, yet there are several other points which seem naturally to demand notice in this place in connection with the experiments formerly detailed. The phænomenon of vital phosphorescence has been regarded as presenting an analogy to the function of respiration, if not connected with it. Thus, in a paper in Tilloch's Magazine (vol. $x$ ) on the Phosphorescence of Ocean-water by Prof. Mitchell of New York, we find the maintenance of the process of phosphorescence ascribed to the presence of a supply of oxygen as conveyed by the arterial blood, the process in fact being compared to respiration as expressed in the following somewhat curious passage :- "The light, then," says he, "which these marine ani- 
mals (the larger Medusæ) exhibit, may be concluded to be produced by a function in them analogous to the respiration of animals which are of larger size and more complicated structure. The only reason why it is visible from their bodies is, that the gelatinous matter of which they consist is transparent. It is not improbable that the same phænomena would be as obvious in the bodies of other creatures, and even of human beings, if the opacity of the materials of which we consist did not hinder the light within us from shining so as to be seen."

From the opinion expressed by Matteucci, he would appear to compare the process of vital phosphorescence to a species of combustion, in which however he also recognizes the necessity for the presence of oxygen. In commenting on the various experiments to which he subjected the phosphorescent matter, he observes, "From all these experiments, I conclude that carbonic acid is produced by the contact with oxygen of the phosphorescent matter alone, separated from the rest of the animal; that the light ceases to be produced when this gas is not present, and that by the contact of the latter, light and a volume of carbonic acid, equal to that of the oxygen consumed, are produced; and that the phosphorescent substance of this insect, when not luminous, does not act on oxygen. It is therefore natural to suppose that the luminous segments of these animals, being enveloped by transparent membranes, and by means of the numerous tracheæ discovered here and there in these animals, atmospheric oxygen is brought in contact with a substance, sui generis, principally composed of carbon, hydrogen, oxygen and azote." And again, "The example of an organic substance which burns in the air by absorbing oxygen and emitting carbonic acid, is not new ; this is the case with decaying wood, with oiled cotton, with finely pulverized charcoal, and with many other substances liable to spontaneous combustion."

On this question, however, there appears to be sorne ground for a difference of opinion. The experiment in which the Noctilucæ continued for many days to emit very vivid scintillations when confined beneath an atmosphere of nitrogen, must be held to militate against the preceding explanation. It is asserted also by Carradori, that the Luciole will shine in a barometrical vacuum, but the experiments of $M$ atteucci on the same point limit this effect to two or three minutes. Admitting therefore the correctness of the latter observation, it may still be questioned whether the effect, even for the time here specified, can be wholly ascribed to the presence of oxygen. Again, when operating on the phosphorescent matter only of 
the glow-worm, this matter being separated from the entire insect, it was found by Matteucci to retain its luminous property for thirty or forty minutes after it was placed in pure hydrogen or carbonic acid gas. Here then we have the phosphorescence continued much longer than in the case of the barometric vacuum; and where, it may be asked, was the supply of oxygen that maintained the combustion above half an hour in this instance, or how can this fact be reconciled with the statement formerly cited, "that the light ceases to be produced when this gas (oxygen) is not present?" In reference to the same point, I may here advert to the increase of light from the effect of carbonic acid on the Nactilucæ formerly described, and may quote also an experiment from the observations of Macartney, in which he states, "Some of the scintillating and bemispherical species of Medusa, contained in a small glass jar, were introduced into the receiver of an air-pump, and the air being exhausted, they shone as usual when shaken; if any difference could be perceived, the light was more easily excited, and continued longer in vacuum *."

A consideration of these and some similar facts would tend rather to the conclusion drawn by Carradori in reference to the experiments of Forster formerly quoted, on which it is remarked, in the 2nd vol. of Tilloch's Magazine, "The observation made by Forster, that the Luciole diffused a more vivid light in oxygen gas than in atmospheric air, does not, according to Carradori, depend upon a combustion more animated by the inspiration of this gas, but on the animals feeling themselves, while in this gas, in a better condition;"-a conclusion, which seems to furnish a view of the question of sufficient importance, to say the least of it, to merit some notice. On the other hand, the instance of the detached luminous segments placed under oxygen, and appearing to absorb a portion of the gas, lends weight to the opinion of Matteucci. It appears, however, by no means certain, even in this case, that the oxygen found to be absorbed, had actually entered into combination with those particles only which are immediately concerned in the production of light; it may, on the contrary, be supposed to have been absorbed also, if not principally, by the other constituents of the organic matter with which the immediate light-emitting particles are combined. And this brings us now to the consideration in the next place of the

Chemical Nature of the Phosphorescent Matter.-In the earlier inquiries respecting the proximate cause of vital phosphorescence, we find that the actual presence of phosphorus

- Phil. Trans. 1810, part 1. p. 285.

Phil. Mag. S. 3. Vol, 35. No. 238. Dec. 1849. 2 E 
in some form of combination was deemed necessary to the display of the luminous property, and in fact that this substance was regarded as the essential ingredient entering into the composition of the phosphorescent matter. Thus it is stated by Carradori, "Behind this receptacle is placed the phosphorus, which resembles a paste having the smell of garlic, and very little taste*." Again, we find Chaptal speaking of it without any hesitation as a phosphoric oil. After noticing the solubility of phosphorus in oils, and more especially in the volatile oils, he observes, "The combination of phosphorus and oil appears to exist naturally in the glow-worm, Lampyris splendidula, Linnæi. Forster of Göttingen observes that the shining matter of the glow-worm is liquid. If the glow-worm be crushed between the fingers, the phosphorescence remains on the finger $t . "$

More recently, again, we find Müller enumerating several facts bearing on the subject, and deducing from them the following conclusion:- " From all the above facts, the opinion of Treviranus appears most probable; namely, that the light is derived from a matter containing phosphorus, which is formed under the influence of light, but, once formed, is in some measure independent of light $\ddagger . "$ Nor am I indeed aware that this notion of the actual presence of phosphorus in the phosphorescent matter of living beings, has ever, previously to the observations of Matteucci, been entirely rejected.

After detailing the influence of the various reagents employed in an elaborate chemical exannination of the phosphorescent matter, Matteucci observes respecting it,- "It does not present any obvious trace of phosphorus; of this fact I have assured myself by calcining this matter several times in a platinum crucible, and by treating the dissolved residue with the tests which indicate the presence of the phosphates. From all we have now stated, we can no longer regard the presence of phosphorus as the cause of the light in these insects $\S$;" and in another place, as before mentioned, it is said to be "a substance, sui generis, principally composed of carbon, hydrogen, oxygen and azote."

On a point like the present, however, where the statement just mentioned is so entirely in opposition to all previous observation, it would seem desirable that we should know with certainty what is the smallest possible amount of phosphorus which is capable, when placed under the most favourable cir-

* Tilloch's Magazine, vol. ii. p. 79.

+ Elements of Chemistry, vol. iii. p. 362.

‡ Elements of Physiology, vol. i. p. 103.

$\S$ p. 182. 
cumstances of combination, of giving rise to the phænomena of phosphorescence. The experiments on which Matteucci grounds his opinion, were no doubt very carefully conducted; yet it may be questioned whether a different result might not be obtained, could a test of such extreme delicacy be rendered applicable in this instance, as we are furnished with by Marsh's apparatus in respect to arsenic. Whilst still upon this subject, I may mention that experimenting some years since with a view to test the theory of the luminous matter of the glowworm being a natural phosphoric oil, and at the same time to imitate artificially the experiment of Forster, I enclosed some phosphoric oil in a delicate membranous sac, which $I$ then introduced into oxygen gas. The result however was anything but favourable to Chaptal's theory, since the phosphorescence, which had been well-marked whilst in atmospheric air, ceased immediately upon the immersion of the bladder in oxygen.

It has been supposed by many experimenters that vital phosphorescence is remotely connected with, or dependent upon, the action which is termed "insolation"; and although we find experiments detailed by Matteucci which at first inclined him to this opinion, yet, on a more careful and exact repetition of them, he was led to admit that "when the insect is placed in its natural conditions with regard to temperature, humidity, \&c., and continues to be nourished, the phosphorescent matter is preserved independent of solar action," a conclusion with which the result of the observations made by myself, in the case of the Noctiluca, entirely corresponds.

In reverting here to the experiments on the Noctiluce, it may be observed that the medium in which they live gave an opportunity for certain experiments which cannot be obtained in the case of the glow-worm-I refer more especially to the influence of galvanism and electro-magnetism formerly described. From the agency of the former however we have seen little or no effect to be produced; whilst the influence of the latter appeared to be only of the nature of a powerful stimulus, not dissimilar in its character from that produced by the strong mineral acids.

An experiment may also be mentioned here, a notice of which, from its negative character, was omitted in its proper place; and is now briefly introduced lest it should be supposed, from the omission, to have been overlooked-I allude to the effect of temperature on the luminous sea-water. On placing a bottle of the sea-water in a vessel containing common spring water at the temperature of $90^{\circ}$, no remarkable effect or increase of light was to be observed; and it has been $2 \mathrm{E} 2$ 
remarked, on the other hand, that when the sea-water is converted into ice it still retains its luminous property. the

It now remains only to offer a few words with respect to

Use of vital phosphorescence, a subject, which, as it has already proved the fertile source of a great amount of speculation, more remarkable for its ingenuity than for any more satisfactory result, it will be my endeavour to dismiss without increasing the accumulated mass of conjecture with which it is already encumbered. As the instances of vital phosphorescence occur amongst so varied and wide a range of the animal creation, it is only reasonable to infer, that in different individual instances this faculty will serve respectively a different purpose. Thus in the highly predaceous luminous shark, the Squalus fulgens, formerly noticed, it may readily be assumed with Mr. Bennett*, "That the phosphorescent power it possesses is of use to attract its prey, upon the same principle as the Polynesian islanders and others employ torches in night fishing." In the insect tribe, again, it has no doubt been correctly described as furnishing "à la lettre, le flambeau de l'amour."

Amongst the lower marine tribes, however, the object of this luminous provision is generally admitted to be much less apparent; and the most probable conjectures that have been formed respecting it, are those by which it is regarded as an engine of defence. Mr. Kirby appears to have viewed it altogether in the latter light; upon which Mr. Bennett has the following remark :- "I cannot believe, with Mr. Kirby, that it serves as a mode of defence; because from what we know of the nature of fishes, this refulgence would be one of the surest means of bringing their probable enemies upon them; and if we are to regard the oeconomy in a destructive point of view, we might rather suppose that it is intended to direct the nocturnal predaceous fishes to their food. *** But it would be unjust to accuse Nature of thus wantonly investing her creatures with a charm that can only tend to their destruction $t . "$ 'The train of argument here employed may be cited as an example of the uncertainty and perhaps error into which the mind may be betrayed, when it quits the plain and sober path of reason, to wander in the field of mere conjecture.

In the instance of the Noctiluca, as already hinted, and for the reasons formerly assigned, it seems probable that this luminous property serves the purpose of defence; though whether this is its sole object, is a question for future investigation to determine. 
Whilst then we have thus cursorily glanced at some of the theories which have been advanced on this subject, we are compelled to confess that even those best established amongst them are far from being in any degree satisfactory. In the instance of the glow-worm, for example, the purpose which this provision fulfills may be said to be universally admitted and agreed upon; yet what sufficient reason can be assigned for such a faculty being conferred almost exclusively on this insect, in preference, as it were, to all others? On this head one cannot do otherwise than express an entire concurrence in the conclusion of Matteucci, that this phænomenon, "in its exceptional character, is one of those mysterious singularities which Nature seems to have distributed amidst the immense variety of beings, almost without any previous attention to the animals on which she bestows them, as if merely for the purpose of constraining us to admire with humility the power of her creative skill."

In concluding this brief and imperfect sketch of a subject involving so many points of interest, my object will have been attained, if what has been here advanced should serve the purpose of rendering somewhat more defined the outline of a picture which yet remains to be filled up in its details, and still invites the hand of the more skilful artist to the undertaking. The subject of vital phosphorescence, as embracing a minute and accurate account of all the known examples of the phænomenon, its causes, its uses, and a yet more critical inquiry into the chemical nature of the phosphorescent process than it has hitherto received, is still open to investigation. And lest any should be inclined to underrate this humble yet interesting department of inquiry, I would venture, in reference to it, to bring to their recollection the high authority of Bacon, who says, "And here men ought to lower their contemplations a little, and inquire into the properties common to all lucid bodies; as this relates to the form of light; how immensely soever the bodies concerned may differ in dignity, as the sun does from rotten wood, or putrefied fish*."

Weston-super-Mare, Sept. 8, 1849.

* On the Doctrine of the Human Soul, p. 113. vol. i., Bacon's Philosophical Works. 